OPEN ACCESS

Edited by:

Drozdstoy Stoyanov Stoyanov, Plovdiv Medical University, Bulgaria

Reviewed by:

Petya Terzivanova, Independent Researcher, Sofia, Bulgaria

Kaloyan Rumenov Stoychev, Medical University Pleven, Bulgaria

${ }^{*}$ Correspondence:

Diogo Telles-Correia tellesdiogo@gmail.com

Specialty section: This article was submitted to Neuroimaging and Stimulation, a section of the journal

Frontiers in Psychiatry

Received: 04 July 2019 Accepted: 30 August 2019 Published: 01 October 2019

Citation:

Castanheira L, Silva C, Cheniaux E and Telles-Correia D (2019) Neuroimaging Correlates of Depression-Implications to Clinical Practice.

Front. Psychiatry 10:703. doi: 10.3389/fpsyt.2019.00703

\section{Neuroimaging Correlates of Depression-Implications to Clinical Practice}

\author{
Lígia Castanheira $^{1,2}$, Carlos Silva ${ }^{1}$, Elie Cheniaux ${ }^{3}$ and Diogo Telles-Correia ${ }^{1,2 *}$ \\ 1 Departamento de Psiquiatria, Faculdade de Medicina, Universidade de Lisboa, Lisbon, Portugal, ${ }^{2}$ Clínica Universitária \\ de Psicologia e Psiquiatria, Faculdade de Medicina, Universidade de Lisboa, Lisbon, Portugal, ${ }^{3}$ Instituto de Psiquiatria da \\ Universidade Federal do Rio de Janeiro (IPUB/UFRJ) \& Faculdade de Ciências Médicas da Universidade do Estado do Rio \\ de Janeiro (FCM/UERJ), Rio de Janeiro, Brazil
}

The growth of the literature about neuroimaging of major depressive disorder (MDD) over the last several decades has contributed to the progress in recognizing precise brain areas, networks, and neurotransmitter processes related to depression. However, there are still doubts about the etiology and pathophysiology of depression that need answering. The authors did a nonsystematic review of the literature using PubMed database, with the following search terms: "major depressive disorder," "neuroimaging," "functional imaging," "magnetic resonance imaging," "functional magnetic resonance imaging," and "structural imaging," being selected the significant articles published on the topic. Anterior cingulate cortex, hippocampus, orbitomedial prefrontal cortex, amygdala basal ganglia, and the cerebellum were the main affected areas across the selected studies. These areas respond to particular neurotransmitter systems, neurochemicals, hormones, and other signal proteins; even more, the evidence supports a distorted frontolimbic mood regulatory pathway in MDD patients. Despite the positive findings, translation to treatment of MDD remains illusory. In conclusion, this article aims to be a critical review of the neuroimaging correlates of depression in clinical research with the purpose to improve clinical practice.

Keywords: major depressive disorder, major depression, magnetic resonance imaging, positron emission tomography, neuroimaging

\section{INTRODUCTION}

Major depressive disorder (MDD) remains a critical disease that greatly impacts the global burden of disease (1). In the absence of biological markers, clinical-based methods continued to be the gold standard to diagnose this disorder (2). In clinical assessment, a nosological classification is used, according to international systems such as the Diagnostic and Statistical Manual of Mental Disorders, Fifth Edition (3) and the International Classification of Diseases, 10th Revision (4). Efforts are continuously made in order to discover dependable biomarkers that clarify the neurobiological mechanisms of psychiatric disorders, identify populations at risk, and provide etiology-based treatments (5).

Studies involving imaging modalities such as structural magnetic resonance imaging (sMRI) and functional magnetic resonance imaging (fMRI) aim to outline brain irregularities accompanying MDD. Moreover, the knowledge provided by the neurobiological components resulting in the 
pathogenesis of MDD can explain the existence of biomarkers for diagnosis, prognosis, and response prediction (5).

In this article, we expect to review the neuroimaging correlates of depression in clinical research. These neuroimaging correlates of depression are presented and discussed from a critical perspective.

\section{METHODS}

The authors performed a nonsystematic review of the literature using PubMed database, with the following search terms: "major depressive disorder," "neuroimaging," "functional imaging," "magnetic resonance imaging," "functional magnetic resonance imaging," and "structural imaging." The literature search was limited to the English language and limited to the dates up to January 2019. There were selected 28 significant articles published on the topic.

\section{RESULTS}

\section{Neuroimaging Modalities in Depression}

Table 1 contains the 26 articles that were selected and are divided by the type of neuroimaging modality and by brain regions studied in the respective article. One article used positron emission tomography (PET) and sMRI modalities, and the other were developed using only one modality. The imaging technic more focused on was fMRI (13 articles), followed by PET (eight articles) and sMRI (four articles).

\section{Functional Magnetic Resonance Imaging}

\section{Resting-State Functional Magnetic Resonance Imaging}

Major depressive disorder is characterized by depressed mood, anhedonia, and feelings of worthlessness; some of these alterations are related to the self, such as rumination (31-33) and autobiographical memory (34). Functional neuroimaging, in this case, fMRI, has achieved to isolate brain regions implicated in self-relation, for example, the anterior cingulate cortex (ACC), the medial prefrontal cortex (MPFC), the posterior cingulate cortex (PCC), dorsomedial thalamus, and the precuneus $(35,36)$.

The default-mode network (DMN) is composed by the lateral and medial parietal cortex, ventral and dorsal medial prefrontal cortices, and areas of the medial and lateral temporal cortices, (11) and is thought to be responsible for processing information related to survival instinct, as well as the capacity to plan the future, desires, and beliefs; all these tasks are related to the self (37-39), functions that are intertwined with the self.

Among the articles cited in fMRI, two demonstrated that subjects with MDD were prone to have an increased activity in the MPFC/ACC areas, as well as diminished activity in the PCC/ precuneus and bilateral angular gyrus areas $(10,23)$.

The cognitive control network (CCN) is an entity responsible for attention-demanding cognitive tasks (40). The affective network $(\mathrm{AN})$ is composed of regions of the ACC (41) responsible for processing emotions (41-46) and is crucial in fear, vigilance, and other emotional responses (43).

One of the articles selected showed increased connectivity in depression in the bilateral dorsomedial prefrontal cortex, which encompasses the DMN, AN, and CCN (10). Greicius et al. (47) show increased functional network connectivity in the thalamus, subgenual cingulate, the precuneus, and the orbitofrontal cortex (OFC) (7). The other two articles demonstrated a significant alteration in global brain networks focusing mainly in the DMN area and in the $\operatorname{AN}(19,21)$.

Regarding effective connectivity of different brain areas, different from functional connectivity, effective connectivity is the effect one neuronal network employs on another network (48). Used an unusual method to measure that connectivity; they used spectral dynamic causal modeling (spDCM) (48). Using spDCM, found a decreased influence from the anterior insula to the middle frontal gyrus in medicated subjects with MDD. An important nexus between the anterior insula and amygdala was also found. A positive correlation between hippocampal node activation and the severity of depression was found, which confirms the relation that the right anterior insula has on depression pathophysiology (48). There was also a meaningful interconnection with activation in the right superior parietal lobule, the right precentral and postcentral gyrus, and in left precuneus $(48,49)$.

\section{Task-Based Functional Magnetic Resonance Imaging}

In depression, emotions tend to be perceived and processed erroneously; for example, good events tend to be assimilated and processed as negative or harmful to the person involved in them (50-54). It is also known that population with MDD has difficulty in recognizing and processing emotion in facial expression (sad vs. happy). The brain networks related to the identification of emotional facial expressions are the fusiform area in the ventral occipitotemporal cortex (55-57); the superior temporal sulcus (58); and the amygdala.

Sheline et al. (18) demonstrated in depressed patients a greater activation of the left amygdala during early stages. Besides, they also confirmed that after 8 weeks of antidepressant treatment (with selective serotonin reuptake inhibitor-sertraline $100 \mathrm{mg} / \mathrm{d}$ ) amygdala activation decreased drastically (18).

$\mathrm{Fu}$ et al. (59) found that presentation of sad faces led to increased activation of the left hippocampus and mainly the amygdala and parahippocampal gyrus. They also reported the activation of the thalamus, dorsal cingulate gyrus, hypothalamus, ventral striatum, and insula. They also found that treatment with fluoxetine $20 \mathrm{mg} / \mathrm{d}$ led to a reduction of the response in the ventral striatum and thalamus (24).

In $\mathrm{fMRI-TB}$, it is also possible to register disturbances in the $\mathrm{DMN}$, Sheline et al. (11) report increased activity in the DMN in depressed subjects. In some proposed tasks, subjects would maintain or increase DMN activity, while control subjects would diminish DMN activity (11).

Translation is the dominion where it is possible to shift data across different subjects to enrich and perfect diagnosis and subsequent treatment, keeping in mind applicability in daily 
TABLE 1 | Neuroimaging modalities in depression.

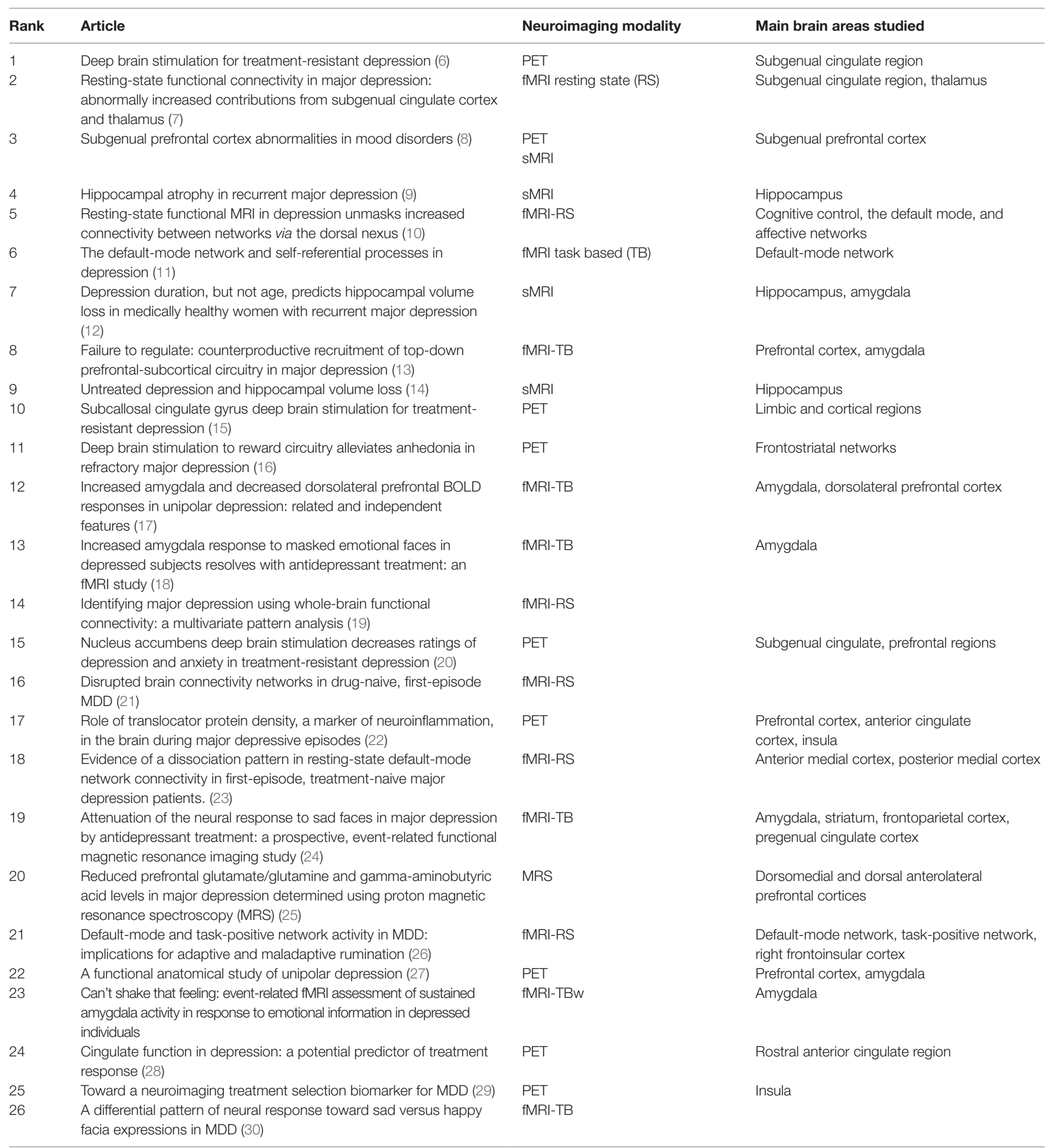

clinical decisions. In psychiatry, it is much more complicated because of the heterogeneity and variability of clinical symptoms; for example, it is highly subjective to measure reliably the level of sadness or anhedonia in two or more people who suffer from MDD, which led to the necessity of devising a hypothesis of translation in depression (60). Stoyanov and colleagues (60) conceptualized an approach of translational cross-validation of psychiatric neurocognitive tests (Von Zerssen's Depression scale) with fMRI scans, expecting to find associations between these methods. Stoyanov and colleagues (61) operationalized this 
concept, and in early findings, there is a weak correlation between the medial frontal cortex (MFC) and MDD subjects; activation in anterior thalamus, hippocampus, and parahippocampal gyrus, areas implicated in the pathophysiology of MDD, was reported as well.

\section{Positron Emission Tomography}

In PET, we are able to estimate brain functional degree on a regional scale. This is possible by quantifying the emission of positrons due to the half-life decay of the various radiopharmaceuticals. Different isotypes permit to evaluate different neurotransmitters receptors, hence its versatility (62).

Relating to the subgenual cingulate region, three articles revealed decreased brain activity/metabolism in patients with depression (8, 20, 28). Mayberg et al. (63) demonstrated that it was possible to diminish the intensity of depressive symptoms, in resistant MDD, through electrical stimulation of the subgenual cingulate white matter (6). Relating to limbic and cortical regions, including frontostriatal networks, two articles revealed altered metabolic activity in those areas after deep brain stimulation of the subcallosal cingulate gyrus/nucleus accumbens in subjects with refractory depressive disease $(15,16)$.

Two articles demonstrated increased microglial activation in patients with depression and identified that response to escitalopram or behavior therapy was predicted by insula activity level $(22,29)$.

\section{Structural Magnetic Resonance Imaging}

Four of the articles that evaluated hippocampal volume identified a volume reduction in patients with $\operatorname{MDD}(9,12$, $14,64)$. Hippocampal volume reduction is observable in MDD $(65,66)$, mainly in the first episode $(67)$. The cognitive decline observed in MDD over the various episodes of illness may be due to volume decrease in the hippocampus (68). Treatment with antidepressants may revert neurocognitive symptoms due to hippocampal volume increase (69). Arnone et al. (70) found that treatment with citalopram led to hippocampal volume increase after 8 weeks of treatment.

Kandilarova, (71) studying the volume of gray matter in affective disorders, found a decrease in gray matter volume, specifically in MDD. The main cluster affected (reduced gray matter) was the MFC and the ACC. The other relevant region was the OFC. Gray matter reduction in the ACC is probably related to the abnormalities found in cognitive and affective regulation, attention, problem solving, motivation, and decision making. Furthermore, the decrease in OFC gray matter explains the alterations in social and emotional behaviors and also in the processing of reward and punishment (71). Kong et al. (72) studied the impact of treatment of MDD with fluoxetine and reported volume increase mainly in the orbitofrontal and the dorsolateral cortices.

Sheline et al. (12) examined the amygdala, with a decreased bilateral amygdala core nuclei volume in patients with recurrent depression. Drevets et al. (8) demonstrated a subgenual prefrontal cortical volume reduction in subjects with depression.

\section{Magnetic Resonance Spectroscopy}

Shen et al. (25) through MRS examined the dorsomedial and dorsal anterolateral prefrontal cortices and concluded that in depressed patients the levels of glutamate, glutamine, and $\gamma$-aminobutyric acid were decreased.

\section{CONCLUSION}

In this article, we reviewed the neuroimaging correlates of depression, in various imaging modalities such as PET, MRI, fMRI, and MRS.

According to the studies we have reviewed, MDD influences major brain areas such as the DMN, AN, CCN, and amygdala and that these affected areas respond to medication, antidepressants.

When evaluating structural differences in brain areas in MDD, we find different variations through multiple brain regions. Nonetheless, evidence has been found that supports changes in gray matter volume in cortical and subcortical regions that might be associated with depressive states. These changes are present through the course of the illness.

The concept of translation is applied globally in medicine, except in psychiatry, mainly due to the heterogeneity of clinical symptoms. Small steps have been made in the field of translational neuroimaging. Nevertheless, they are promising. Despite advances in research on the genetic neuroimaging, psychoneuroimmunology, and multimodal imaging, further studies are necessary to confirm this concept in all these modalities, diminishing the gap between neuroscience and clinical psychiatry.

A significant weakness of the reviewed studies is that they generally have a small population, so we have to be careful in drawing conclusions to the general population. In addition, different studies focus on different brain areas, not being able to identify a pathognomonic finding of MDD. We also fail to conclude whether such differences represent a congenital structural anomaly, a result of the disease, or a compensatory adaptation.

The tendency to evaluate particular brain regions independently is an explicit limitation, as the various areas are interrelated. The circuit-based analysis will provide a foundation for behavioral process analysis. This will facilitate the identification and analysis of MDD and psychiatric symptoms, mostly subjective, but that is used in clinical practice.

More studies, with larger populations, and ideally focusing on circuits other than specific brain areas, will be necessary to draw further conclusions.

Studies including subjects not medicated might enlighten about MDD-related brain abnormalities, without possible unwanted effects that the medication might introduce.

\section{AUTHOR CONTRIBUTIONS}

All authors of this study had an active role in the manuscript and have thoroughly read the final manuscript. 


\section{REFERENCES}

1. Murray CJL, Lopez AD. Measuring the global burden of disease. $N$ Engl $J$ Med (2013) 369(5):448-57. doi: 10.1056/NEJMra1201534

2. Mayes R, Horwitz AV. DSM-III and the revolution in the classification of mental illness. J Hist Behav Sci (2005) 41(3):249-67. doi: 10.1002/jhbs.20103

3. American Psychiatric Association. Diagnostic and statistical manual of mental disorders: DSM-5. 5th ed. Washington D.C: American Psychiatric Association (2013). doi: 10.1176/appi.books.9780890425596

4. World Health Organization. The ICD-10 classification of mental and behavioural disorders: clinical description and diagnostic guidelines. Geneve: World Health Organization (1992).

5. Fu CHY, Costafreda SG. Neuroimaging-based biomarkers in psychiatry: clinical opportunities of a paradigm shift. Can J Psychiatry (2013) 58(9):499508. doi: $10.1177 / 070674371305800904$

6. Schläpfer TE, Kayser S. Deep brain stimulation for treatment-resistant depression. Klin Neurophysiol (2014) 45(2):113-7. doi: 10.1055/s-00341375605

7. Greicius MD, Flores BH, Menon V, Glover GH, Solvason HB, Kenna H, et al. Resting-state functional connectivity in major depression: abnormally increased contributions from subgenual cingulate cortex and thalamus. Biol Psychiatry (2007) 62(5):429-37. doi: 10.1016/j.biopsych. 2006.09.020

8. Drevets WC, Price JL, Simpson JR, Jr, Todd RD, Reich T, Vannier M, et al. Subgenual prefrontal cortex abnormalities in mood disorders. Nature (1997) 386(6627):824-7. doi: 10.1038/386824a0

9. Vannier MW, Wang PW, Gado MH, Csernansky JG, Sheline YI. Hippocampal atrophy in recurrent major depression. Proc Natl Acad Sci (2002) 93(9):390813. doi: 10.1073 /pnas.93.9.3908

10. Sheline YI, Price JL, Yan Z, Mintun MA. Resting-state functional MRI in depression unmasks increased connectivity between networks via the dorsal nexus. Proc Natl Acad Sci (2010) 107(24):11020-5. doi: 10.1073/ pnas. 1000446107

11. Sheline YI, Barch DM, Price JL, Rundle MM, Vaishnavi SN, Snyder AZ, et al. The default mode network and self-referential processes in depression. Pnas (2009) 106(6):1942-7. doi: 10.1073/pnas.0812686106

12. Sheline YI, Sanghavi M, Mintun MA, Gado MH. Depression duration but not age predicts hippocampal volume loss in medically healthy women with recurrent major depression. J Neurosci (1999) 19(12):5034-43. doi: 10.1523/ JNEUROSCI.19-12-05034.1999

13. Urry HL, van Reekum CM, Davidson RJ, Johnstone T, Kalin NH. Failure to regulate: counterproductive recruitment of top-down prefrontal-subcortical circuitry in major depression. J Neurosci (2007) 27(33):8877-84. doi: 10.1523/JNEUROSCI.2063-07.2007

14. Sheline YI, Gado MH, Kraemer HC. Untreated depression and hippocampal volume loss. Am J Psychiatry (2003) 160(8):1516-8. doi: 10.1176/appi.ajp. 160.8 .1516

15. Kennedy SH, Giacobbe P, Hamani C, Lozano AM, Mayberg HS, Craddock RC. Subcallosal cingulate gyrus deep brain stimulation for treatment-resistant depression. Biol Psychiatry (2008) 64(6):461-7. doi: 10.1016/j.biopsych.2008.05.034

16. Schlaepfer TE, Cohen MX, Frick C, Kosel M, Brodesser D, Axmacher N, et al. Deep brain stimulation to reward circuitry alleviates anhedonia in refractory major depression. Neuropsychopharmacology (2008) 33(2):36877. doi: $10.1038 /$ sj.npp. 1301408

17. Siegle GJ, Thompson W, Carter CS, Steinhauer SR, Thase ME. Increased amygdala and decreased dorsolateral prefrontal BOLD responses in unipolar depression: related and independent features. Biol Psychiatry (2007) 61(2):198-209. doi: 10.1016/j.biopsych.2006.05.048

18. Sheline YI, Barch DM, Donnelly JM, Ollinger JM, Snyder AZ, Mintun MA. Increased amygdala response to masked emotional faces in depressed subjects resolves with antidepressant treatment: an fMRI study. Biol Psychiatry (2001) 50(9):651-8. doi: 10.1016/S0006-3223(01)01263-X

19. Zeng LL, Shen H, Liu L, Wang L, Li B, Fang P, et al. Identifying major depression using whole-brain functional connectivity: a multivariate pattern analysis. Brain (2012) 135(5):1498-507. doi: 10.1093/brain/aws059

20. Bewernick BH, Hurlemann R, Matusch A, Kayser S, Grubert C, Hadrysiewicz B, et al. Nucleus accumbens deep brain stimulation decreases ratings of depression and anxiety in treatment-resistant depression. Biol Psychiatry (2009) 67(2):110-6. doi: 10.1016/j.biopsych.2009.09.013

21. Zhang J, Wang J, Wu Q, Kuang W, Huang X, He Y, et al. Disrupted brain connectivity networks in drug-naive, first-episode major depressive disorder. Biol Psychiatry (2011) 70(4):334-42. doi: 10.1016/j.biopsych.2011.05.018

22. Setiawan E, Wilson AA, Mizrahi R, Rusjan PM, Miler L, Rajkowska G, et al. Role of translocator protein density, a marker of neuroinflammation, in the brain during major depressive episodes. JAMA Psychiatry (2015) 72(3):26875. doi: 10.1001/jamapsychiatry.2014.2427

23. Zhu X, Wang X, Xiao J, Liao J, Zhong M, Wang W, et al. Evidence of a dissociation pattern in resting-state default mode network connectivity in first-episode, treatment-naive major depression patients. Biol Psychiatry (2012) 71(7):611-7. doi: 10.1016/j.biopsych.2011.10.035

24. Fu CHY, SWilliams SCR, Cleare AJ, Brammer MJ, Walsh ND, Kim J, et al. Attenuation of the neural response to sad faces in major depression by antidepressant treatment. Arch Gen Psychiatry (2004) 61(9):877. doi: 10.1001/archpsyc.61.9.877

25. Shen J, Tumonis T, van der Veen JW, Drevets WC, Meyers N, Hasler G. Reduced prefrontal glutamate/glutamine and $\gamma$-aminobutyric acid levels in major depression determined using proton magnetic resonance spectroscopy. Arch Gen Psychiatry (2007) 64(2):193. doi: 10.1001/archpsyc.64.2.193

26. Furman DJ, Thomason ME, Gotlib IH, Chang C, Dennis E, Hamilton JP. Default-mode and task-positive network activity in major depressive disorder: implications for adaptive and maladaptive rumination. Biol Psychiatry (2011) 70(4):327-33. doi: 10.1016/j.biopsych.2011.02.003

27. Price JL, Preskorn SH, Carmichael ST. Anatomical study of unipolar depression. Neurol Surg (1992) 12:3628-41. doi: 10.2217/bmm.11.1

28. Mayberg HS, Brannan SK, Mahurin RK, Jarebek PA, Brickman JS, Tekell JL, et al. Cingulate function in depression: a potential predictor of treatment response. Neuroreport (1997) 3(8(4):1057-61. doi: 10.1097/00001756-199703030-00048

29. McGrath CL, Kelley ME, Holtzheimer PE, Dunlop BW, Craighead WE, Franco AR, et al. Toward a neuroimaging treatment selection biomarker for major depressive disorder. JAMA Psychiatry (2013) 70(8):821-9. doi: 10.1001/jamapsychiatry.2013.143

30. Surguladze S, Brammer MJ, Keedwell P, Giampietro V, Young AW, Travis MJ, et al. A differential pattern of neural response toward sad versus happy facial expressions in major depressive disorder. Biol Psychiatry (2005) 57(3):201-9. doi: 10.1016/j.biopsych.2004.10.028

31. Grimm S, Ernst J, Boesiger P, Schuepbach D, Hell D, Boeker H, et al. Increased self-focus in major depressive disorder is related to neural abnormalities in subcortical-cortical midline structures. Hum Brain Mapp (2009) 30(8):2617-27. doi: 10.1002/hbm.20693

32. Northoff G. Psychopathology and pathophysiology of the self in depressionneuropsychiatric hypothesis. J Affect Disord (2007) 104(1-3):1-14. doi: 10.1016/j.jad.2007.02.012

33. Rimes KA, Watkins E. The effects of self-focused rumination on global negative self-judgements in depression. Behav Res Ther (2005) 43(12):167381. doi: 10.1016/j.brat.2004.12.002

34. Sumner JA, Griffith JW, Mineka S. Overgeneral autobiographical memory as a predictor of the course of depression: a meta-analysis. Behav Res Ther (2010) 48(7):614-25. doi: 10.1016/j.brat.2010.03.013

35. Greicius MD, Krasnow B, Reiss AL, Menon V. Functional connectivity in the resting brain: a network analysis of the default mode hypothesis. Proc Natl Acad Sci (2003) 100(1):253-8. doi: 10.1073/pnas.0135058100

36. Raichle ME, MacLeod AM, Snyder AZ, Powers WJ, Gusnard DA, Shulman GL. A default mode of brain function. Proc Natl Acad Sci USA (2001) 98:676-82. doi: 10.1073/pnas.98.2.676

37. Rogers MA, Kasai K, Koji M, Fukuda R, Iwanami A, Nakagome K, et al. Executive and prefrontal dysfunction in unipolar depression: a review of neuropsychological and imaging evidence. Neurosci Res (2004) 50(1):1-11. doi: 10.1016/j.neures.2004.05.003

38. Neuroscience A, Davidson RJ, Pizzagalli D, Nitschke JB, Putnam K. Depression: perspectives from. Annu Rev Psychol (2002) 53(1):545-74.

39. Fitzgerald PB, Oxley TJ, Laird AR, Kulkarni J, Egan GF, Daskalakis ZJ. An analysis of functional neuroimaging studies of dorsolateral prefrontal cortical activity in depression. Psychiatry Res - Neuroimaging (2006) 148(1):33-45. doi: 10.1016/j.pscychresns.2006.04.006 
40. Corbetta M, Shulman GL. Control of goal-directed and stimulus-driven attention in the brain. Nat Rev Neurosci (2002) 3(3):201-15. doi: 10.1038/ nrn755

41. Bush G, Luu P, Posner MI. Bush_2000_conitive and emotional influence in anterior cingulate cortex. Trends Cognit Sci (2000) 4(6):215-22. doi: 10.1016/ S1364-6613(00)01483-2

42. Johansen-Berg H, Gutman DA, Behrens TE, Matthews PM, Rushworth MF, Katz E, et al. Anatomical connectivity of the subgenual cingulate region targeted with deep brain stimulation for treatment-resistant depression. Cereb Cortex (2008) 18(6):1374-83. doi: 10.1093/cercor/bhm167

43. Öngür D, Ferry AT, Price JL. Architectonic subdivision of the human orbital and medial prefrontal cortex. J Comp Neurol (2003) 460(3):425-49. doi: $10.1002 / \mathrm{cne} .10609$

44. Kennedy SH, Evans KR, Krüger S, Mayberg HS, Meyer JH, McCann S, et al. Changes in regional brain glucose metabolism measured with positron emission tomography after paroxetine treatment of major depression. Am J Psychiatry (2001) 158(6):899-905. doi: 10.1176/appi.ajp.158.6.899

45. Phillips ML, Drevets WC, Rauch SL, Lane R. Neurobiology of emotion perception II: implications for major psychiatric disorders. Biol Psychiatry (2003) 54(5):515-28. doi: 10.1016/S0006-3223(03)00171-9

46. Mayberg HS, Liotti M, Brannan SK, McGinnis S, Mahurin RK, Jerabek PA, et al. Reciprocal limbic-cortical function and negative mood: converging PET findings in depression and normal sadness. Am J Psychiatry (1999) 156(5), 675-82. doi: 10.1176/ajp.156.5.675

47. Greicius, Michael D. et al. Resting-State Functional Connectivity in Major Depression: Abnormally Increased Contributions from Subgenual Cingulate Cortex and Thalamus. Biol Psychiatry, 62(5):429-437. Published in 2007. doi: 10.1016/j.biopsych.2006.09.020

48. Kandilarova S, Stoyanov D, Kostianev S, Specht K. Altered resting state effective connectivity of anterior insula in depression. Front Psychiatry (2018) 9:1-7. doi: 10.3389/fpsyt.2018.00083

49. Stoyanov D, Kandilarova S, Borgwardt S, Stieglitz RD, Hugdahl K, Kostianev S. Psychopathology assessment methods revisited: on translational cross-validation of clinical self-evaluation scale and fMRI. Front Psychiatry (2018) 9:1-8. doi: 10.3389/fpsyt.2018.00021

50. Beck AT, Rush AJ, Shaw B, Emery G. Cognitive therapy of depression. New York, NY: Guilford Publications (1979).

51. TeasdaleJD.Negativethinkingindepression:cause,effect,orreciprocalrelationship? Adv Behav Res Ther (1983) 5(1):3-25. doi: 10.1016/0146-6402(83)90013-9

52. Segal ZV, Williams JM, Teasdale JD, Gemar M. A cognitive science perspective on kindling and episode sensitization in recurrent affective disorder. Psychol Med (2009) 26(02):371. doi: 10.1017/S0033291700034760

53. Watkins PC, Vache K, Verney SP, Mathews A. Unconscious mood-congruent memory bias in depression. J Abnorm Psychol (1996) 105(1):34-41. doi: 10.1037/0021-843X.105.1.34

54. Watkins PC, Martin CK, Stern LD. Unconscious memory bias in depression: perceptual and conceptual processes. J Abnorm Psychol (2000) 109(2):282-9. doi: 10.1037/0021-843X.109.2.282

55. Haxby J, Horwitz B, Ungerleider LG, Maisog JM, Pietro P, Grady CL. The functional organization of human extrastriate cortex.pdf. J Neurosci (1994) 14(11):6336-53. doi: 10.1523/JNEUROSCI.14-11-06336.1994

56. Puce A, Allison T, Gore JC, McCarthy G. Face-sensitive regions in human extrastriate cortex studied by functional MRI. J Neurophysiol (2017) 74(3):1192-9. doi: 10.1152/jn.1995.74.3.1192

57. Kanwisher N, Mcdermott J, Chun MM. The fusiform face area: a module in human extrastriate cortex specialized for face perception. J Neurosci (1997) 17(11):4302-11. doi: 10.1109/CDC.2005.1583375

58. Puce A, Allison T, Bentin S, Gore JC, McCarthy G. Temporal cortex activation in humans viewing eye and mouth movements. J Neurosci (2018) 18(6):2188-99. doi: 10.1523/JNEUROSCI.18-06-02188.1998
59. Fu CHY, Williams SCR, Cleare AJ, Brammer MJ, Walsh ND, Kim J, et al. Attenuation of the Neural Response to Sad Faces in Major Depressionby Antidepressant Treatment. Arch Gen Psychiatry. 2004 61(9):877. doi: 10.1001/archpsyc.61.9.877

60. Stoyanov D, Kandilarova S, Borgwardt S. Translational functional neuroimaging in the explanation of depression. Balkan Med J (2017) 34(6):493-503. doi: 10.4274/balkanmedj.2017.1160

61. Stoyanov D, Kandilarova S, Sirakov N, Stoeva M, Velkova KG, Kostianev SS. Towards translational cross-validation of clinical psychological tests and fMRI: experimental implementation. Comptes Rendus L'Academie Bulg des Sci (2017) 70(6):879-84.

62. Gong B, Naveed S, Hafeez DM, Afzal K, Majeed S, Abele J, et al. Neuroimaging in psychiatric disorders: a bibliometric analysis of the 100 most highly cited articles. J Neuroimaging (2019) 29(1):14-33. doi: 10.1111/jon.12570

63. Mayberg HS, Lozano AM, Voon V, McNeely HE, Seminowicz D, Hamani C, et al. Deep brain stimulation for treatment-resistant depression. (2005). 45(5):651-60. doi: 10.1016/j.neuron.2005.02.014

64. Bremner JD, Narayan M, Anderson ER, Staib LH, Miller HL, and Charney DS. hippocampal volume reduction dep.pdf. Am J Psychiatry (2000) 157:115-117. doi: 10.1176/ajp.157.1.115

65. Kempton MJ. Structural neuroimaging studies in major depressive disorder. Arch Gen Psychiatry (2011) 68(7):675. doi: 10.1001/archgenpsychiatry. 2011.60

66. Zhao YJ, Du MY, Huang XQ, Lui S, Chen ZQ, Liu J, et al. Brain grey matter abnormalities in medication-free patients with major depressive disorder: a meta-analysis. Psychol Med (2014) 44(14):2927-37. doi: 10.1017/ S0033291714000518

67. Cole J, Costafreda SG, McGuffin P, Fu CHY. Hippocampal atrophy in first episode depression: a meta-analysis of magnetic resonance imaging studies. J Affect Disord (2011) 134(1-3):483-7. doi: 10.1016/j.jad.2011.05.057

68. Rot MAH, Mathew SJ, Charney DS. Neurobiological mechanisms in major depressive disorder. Can Med Assoc J (2009) 180(3):305-13. doi: 10.1503/ cmaj.080697

69. Frodl T, Jäger M, Smajstrlova I, Born C, Bottlender R, Palladino T, et al. Effect of hippocampal and amygdala volumes on clinical outcomes in major depression: a 3-year prospective magnetic resonance imaging study. J Psychiatry Neurosci (2008) 33(5):423-30.

70. Arnone D, McKie S, Elliott R, Juhasz G, Thomas EJ, Downey D, et al. State-dependent changes in hippocampal grey matter in depression. Mol Psychiatry (2013) 18(12):1265-72. doi: 10.1038/mp.2012.150

71. Kandilarova S. Reduced grey matter volume in frontal and temporal areas in depression: a voxel based morphometry study. (2019) 1-11. doi: 10.20944/ preprints201902.0078.v1

72. Kong L, Wu F, Tang Y, Ren L, Kong D, Liu Y, et al. Frontal-subcortical volumetric deficits in single episode, medication-naïve depressed patients and the effects of 8 weeks fluoxetine treatment: a VBM-DARTEL study. PLoS One (2014) 9(1):e79055. doi: 10.1371/journal.pone.0079055

Conflict of Interest: The authors declare that the research was conducted in the absence of any commercial or financial relationships that could be construed as a potential conflict of interest.

The handling editor declared a past co-authorship with one of the authors DT-C.

Copyright $\odot 2019$ Castanheira, Silva, Cheniaux and Telles-Correia. This is an openaccess article distributed under the terms of the Creative Commons Attribution License (CC BY). The use, distribution or reproduction in other forums is permitted, provided the original author(s) and the copyright owner(s) are credited and that the original publication in this journal is cited, in accordance with accepted academic practice. No use, distribution or reproduction is permitted which does not comply with these terms. 